\title{
Confronting Historical Paradigms: Peasants, Labor and the Capitalist World System in Africa and Latin America, edited by Frederick Cooper. Madison: Uni- versity of Wisconsin Press, 1993. viii 430 pp.
}

\section{Dependency and Development: An Introduction to the Third World, by Ted Lewellen. Westport: Bergin and Garvey, 1995. xi, 271 pp.}

\author{
Reviewed by Richard K. Reed, Department of Sociology and Anthro- \\ pology, Trinity University.
}

The 1970s saw a burst of insight into the historical development of global economic and political relations. Previously, social science had envisioned the world as divided into two distinct sectors, the "traditional" and the "modern." Radical critiques of that paradigm recognized that the centers of a world system manipulate and expropriate wealth from "underdeveloped" countries. In turn, these reformulations have been roundly criticized over the last two decades. The world capitalist system has been shown to be less a monolith than a pastiche of struggles in which local conditions and groups exert considerable power. Moreover, our concept of world structures has come under attack as rooted in time and place. We have come to see our models as subjective representations of our world, rather than objective realities.

It is perhaps a fitting moment in the historical development of our own knowledge to take account of the state of our concepts. The two books offered here explore these models of the world system, considering the recent advances. These authors do more than consider the state of the art, they lay the groundwork for further developments and new understandings.

The first of these books, Confronting Historical Paradigms: Peasants, Labor and the Capitalist World System in Africa and Latin America, proposes to re-evaluate our paradigms for understanding world history. Five established scholars discuss the theories and models for African and Latin American development. They seek to bridge these two continents and compare the project of workers in these two sectors of the world system.

The work sets its task as more than an explication of the historical relation between peasants and labor in these regions. It redefines these processes, using recent advances in historiography and cultural analysis to evaluate the promises and pitfalls of the models. It does not engage directly with the conventional paradigms of modernization theory; nor does it try to provide the final and ultimate model to supplant the more recent critiques of radical models. This work attempts to provide voices to the growing discussions of history and change in a global perspective. In short, it is designed to stimulate new thinking and work on the topic.

The work successfully opposes discussions of African and Latin American literatures. This allows the reader to understand the areas of commonalties and the different paths that the two have traveled over the last decades. Moreover, by discussing concepts (e.g., "peasant") and case materials from two continents, it allows the reader to appreciate historical differences between the areas. This can account for some, but nor all, of the theoretical incongruities.

In the introductory essay, Stern points out that the last two decades have seen splin- 
tering in the historical study of labor and peasantry. First, the objective stance of traditional historiography has been thoroughly criticized, replaced by an awareness of the analysts' perspective. Second, the social history movement has shifted the focus of analysis to the power of non-elite sectors. Third, the specialization of historians has created scholarly myopia, obstructing the grand vision of writing world history. This volume, then, seeks to rediscover the common ground in historical analysis of labor's relations to world structures.

Stern finds the common ground in the dialogue between diverse voices and experiences. On one hand, the voices of anthropologists, historians, Latin Americanists and Africanists have brought diverse perspectives to the study of these issues. On the other hand, the project of this social analysis has shown that the monolithic world system is more accurately described as myriad local experiences. Diverse forms of resistance and accommodation influence the relations that develop. The cadence of these voices, attended to in unison, provides "reverberations" that make the larger themes and issues evident.

In the first analytic essay, Stern evaluates Wallerstein's model from a peripheral perspective, focusing on Latin American sugar and silver production in the sixteenth and seventeenth century. Wallerstein's model improved our understanding of capitalist market relations. However, Stern points out that it misses important local factors that constrained and patterned the development of sugar and silver economies. Stern posits that two additional local factors need to be integrated into our understanding of world history: popular strategies of resistance and the struggles of local mercantile elites.

Shifting to Africa, Cooper offers a comparative perspective on global economic history. The basic essay was written in 1980 and passes the test of time in its clarity and comprehensiveness. Cooper follows his original piece with a more current postscript that analyzes recent theoretical contributions to the understanding of African development problems.

He asks succinctly "But is there anything in this trend toward cultural and linguistic analysis that is relevant to the "dismal science" which was the subject of this essay?" (1993:195). He answers the rhetorical question with qualified affirmation, citing studies that explore the power of development concepts to define relations between the center and periphery. For example, Cooper points to Ferguson's (1990) study of Lesotho, which was defined as "politically and economically isolated." This blinded the world to a century of exploitation it received at the hands of world and state powers.

The third and fourth sections of this book are more conceptually focused. They rethink the concept of "peasant" as it applies to the analysis of both African and Latin American societies. Isaacman points out that, in Africa, the concept of "peasant" has always been problematic. In contrast to its use in Latin America, where it referred to the cultural aspects of rural groups, in Africa the term took on a more political economic character. Farmers were "peasants" in three respects: their relation to land (small holder or tenant); type of production (subsistence); and their relation to the elite (surplus extractors). Isaacman integrates recent awareness of the struggles in which this group is engaged. Thus, peasants are recognized as not only shielding critical resources from the exploitative elites, but with the political space for localized resistance.

In Roseberry's essay, "Beyond the Agrarian Question in Latin America," he reassesses the structural focus of the debates about Latin American peasantry. The radical critique of modernization theory focused on dependent relations emanating from the center of world capitalism, and gave the impression that a general history was imposed on "from above". Attracted in the 1980s to the historical and systemic concerns of dependency and world-systems theories, a cohort of scholars transformed them. Anthropologists and historians brought an awareness of the profound complexity of class and ethnic relations that defy and confound categorization. These called attention to the actions of local groups and the experience of individual actors. Peasants relate to their political worlds in a complex montage of resistance and accommodation. These are reactions to, but not determined by, 
the larger world of which they are a part.

Mallon provides the final and concluding chapter to this volume. She points out that the last generation scholars critiqued the dual structure of modernization theory, highlighting links of central powers to Latin American and African societies. The present generation of scholars have discovered diverse voices and case studies that challenge the universalist paradigms of dependency and world systems theories. Our task, therefore, is to find the underlying resonance in the variety of historical experiences over the two continents and four centuries.

Mallon points out the current study of universalist paradigms make us aware of the contestation of knowledge, discourse and culture. These recognize how local power negotiates with larger structures. As long as awareness of these issues remains the sole property of the intelligentsia of so-called developed countries however, it reinforces the imperialism and power differentials of the past.

As a unified piece, this work is as important for the generalist as for those who have been engaged with the recent material. These articles have much to offer scholars who immersed themselves in the dependency and articulation of modes of production debates, then abandoned them as gendered, ethnic and post-structuralist models grew in intellectual fashion. The volume reviews the strengths of these earlier paradigms from the vantage point of our present skepticism. It allows us to reintegrate them into the eclectic perspectives that we use to understand our increasingly complex world.

Dependency and Development: An Introduction to the Third World is an introductory text, seeking to explain the third world and its problems to the newcomer. Author Ted Lewellen describes the relations between rich and poor nations, and the relentless change in the modern world. Using a perspective that draws on both dependency and development theories, Lewellen explores issues in Third World development, including population growth, environmental problems and human rights.

As an analytic overview of the field, the book both describes and explains international relations. The work introduces and evaluates theoretical constructs of international development, focusing on those that highlight relations in which more powerful states influence conditions internal to weaker nations.

As a text, the book is suitable for advanced undergraduates, established graduate students, or the informed generalist. The author defines basic concepts, such as "imperialism" and "colonialism," which gives the newcomer the tools to begin to think about different structures for international relations. It also evaluates different models of these relations, which highlight the shifting focus of development theory over the last decades. Finally, for the more advanced reader, this text explores a series of case studies, in which the models highlight critical relations between powerful and weaker countries.

First, the book sets out to define its subject for the introductory reader. To do so, the author falls back on the term "Third World." Despite its intellectual baggage, the concept points to a variety of important social, economic, and political differences between powerful nations and "the rest." Lewellen is a cultural anthropologist, and this affiliation is clear in the multifaceted nature of this focus. He has drawn on political science, economics and history, using case studies from around the world. Thus, in analyzing the "Third World," the work is interdisciplinary in both tone and substance.

The book provides a brief world history of the broad international connections that were formed long ago. This underscores the actions of powerful nations that have driven much world history. While outlining the relentless drive toward connection, Lewellen makes an effort to point to the positive and the negative impact of these relations.

This book also introduces the reader to the variety of theoretical formulations that have defined the development literature. Lewellen provides a brief and cogent description of modernization, dependency, and world systems theories. He argues that no single theory can explain the complex present. Besides exploring the power of international rela- 
tions, he points to the powerful forces at work within weaker nations. Thus, the book attempts a synthetic approach to understand the changing world of today.

The heart of this book is the exploration of six social issues understood in linkages between local and international levels. The first analyzes the internal economies of third world countries. The discussion of domestic economy challenges traditional perspectives of poverty, which rely on indices of GNP, and points out that the analysis needs to attend the distribution of income as well. In addition to the agricultural and industrial sectors, this points to the third important economic sector including both the informal economy and government employment. This chapter relates the organization and problems of domestic economies of third world countries to the traditional inner-directed models, notably the basic needs and the import-substitution models.

The fifth chapter outlines the situation of third world economies in the international economic order. This discusses the imbalance in the world marketplace, then outlines neoliberal and Asian models for extricating national economies from these ties. It concludes with the international debt crisis of the 1980s and the new world economic order.

The sixth chapter outlines the link between economics and politics in the developing world. The discussion uses game theory to point to the conflicting agendas of the various actors, and the means that political elites use to dominate state bureaucracies. The seventh chapter focuses on the demographic problems faced by many Third World countries: population growth, migration and urbanization. Lewellen's discussion on population focuses on three aspects. He surveys demographic arguments of world population growth, showing that economic insecurity leads to high fertility rates in Third World countries. This discussion also points to the problems created by urban migration in countries with little infrastructures and declining employment. Finally, the discussion of demography discusses the recent rise in refugee populations, and the particular problems they create for state systems with few political and economic resources.

The last two issues discussed in this book move to the contemporary debates about the sustainability of development and abuses of human rights. Current development is rapidly destroying the resources on which it depends. Urban air and water are rendered toxic by industrial development; expanding rural economies destroy forests and leave deserts in their wake. The discussion of the environment ends on a cautiously optimistic note, pointing to the recent policy changes in multilateral banks drafted in response to international concern.

The last issue discussed in this text is human rights. Lewellen points out that genocide, torture, and murder are common in many developing areas. Ethnic differences, economic pressures, and the consolidation of state control create an environment where respect for humanity is often overridden by the mandate of development. Indigenous groups, most especially, have suffered from their relations with this process of change and development.

The final chapter in Dependency and Development reviews the mixed outcomes of world economic growth and political consolidation. It points to the dramatic increase in health, education, and democratic institutions over the last decades, while recognizing that problems continue and, in some ways, are exacerbated.

This book provides a clear and balanced discussion of the problems and prospects inherent in our growing world. It is informed by our contemporary understanding of the political, economic and ecological linkages between the First and the Third Worlds. It shows that the problems of the Third World are not a necessary aspect of world history, but were created in relations between developed and developing nations. The book is especially useful in being aware of the demise of the Soviet state, and the dramatic shifts in the world's balance of power and ideological landscape.

At a theoretical level, this book attempts to go beyond the distinct perspectives of dependency and modernization theories, by synthesizing them into a single approach. The 
result leaves the reader with an understanding of the complexity of the problem, without the coherence of a single approach.

In many ways, this book fails to break out of the conventional molds for development and underdevelopment studies. For example, by choosing the concept of the "Third World" as the unit of his analysis, Lewellen steps into the quagmire that has hampered previous discussions. The intransigent nature of these problems calls for a new concept.

Both books offer useful perspectives on the current state of international affairs and world stratification. Whereas the former book provides the advanced social scientist with much to think about, the latter starts yet another generation thinking about the problem.

\section{Feminist Political Ecology: Global Issues and Local Experiences. Dianne Rocheleau, Barbara Thomas- Slayter and Esther Wangari (eds) London and New York: Routledge, 1996. xviii, 327 pp.}

\section{Reviewed by Helen Ross, Centre for Resource and Environmental Studies, Australian National University, Canberra.}

Given the theoretical contribution of gender studies to the field of political economy, this collection is a timely development in political ecology and in feminist theories. It is an equally useful set of case studies in development- -and especially sustainable development--studies, human ecology, anthropology, rural sociology, and social movements, well worth recommending to students in any of these fields as a course text.

In their opening chapter, the editors explain succinctly the positions and differences of a number of schools of feminist scholarship and activism on the environment. They describe their conceptual framework of 'feminist political ecology' as linking insights from feminist cultural ecology and political ecology with those of feminist geography and feminist political economy.

Feminist political ecology treats gender as a critical variable in shaping resource access and control, interacting with class, caste, race, culture, and ethnicity to shape processes of ecological change, the struggle of men and women to sustain ecologically viable livelihoods, and the prospects of any community for "sustainable development" (p. 4).

They focus on the gendered knowledge used in the creation and maintenance of healthy environments, gendered environmental rights and responsibilities, including property, resources, space, legal and customary rights, and gendered environmental politics and grassroots activism. These dimensions provide a general framework for analysis, around which the case studies are grouped.

Unusual for an edited collection, the case study chapters are almost seamless in their styles of analysis and writing. Most of the case studies artfully combine analytical comment with detail that enables one to visualise the situation.

Another strength of the organisation of the case studies is that whereas one theme, such as activism, predominates in each section, the other themes also permeate the analyses. For instance, Bru-Bistuer's Spanish case studies outlining women's participation in oppositional campaigns to industrial waste disposal also emphasises women's understandings of the environmental issues, focused on concerns for health. Miller, Hallstein and Quass' West Harlem case study describes a community (with substantial female leadership) that opposed the siting of a sewerage treatment plant in their area. It goes on to 